\title{
Analysis of e-Recruitment System Design
}

\author{
Fanny Ramadhani*, Muhammad Zarlis \\ Universitas Sumatera Utara, FakultasIlmuKomputerdanTeknologiInformasi, Medan, Indonesia. \\ * Corresponding author. Tel.: 085297900055; email: fannyramadhani58@yahoo.com, m.zarlis@usu.ac.id \\ Manuscript submitted February 12, 2018; accepted May 28, 2018. \\ doi: 10.17706/ijeeee.2019.9.1.38-45
}

\begin{abstract}
The process of applying for a job is a first step for unemployment to get a job who matches the criteria. An e-recruitment system such as LinkedIn, Reed, and Indeed is a tool for prospective workers looking for jobs. On this site, workers must register the email address, name, type of bachelor and salary desired. After that, system will send company's link that is offers vacancies to the email of candidates, so the jobsekeer can directly register to the system. However, the system is ineffective because the prospective worker must register itself on the website where the e-recruitment site only provides such services. In contrast to prospective workers and e-recruitment systems, recruiters (firms) also have bigger problems. To open the selection of new recruiting candidates, the company has to spend a lot of energy, time and money. From that point, this paper is designed to create heading posts for users (prospective workers) and companies to be on the same system. It will help users in finding work and help companies in finding workers who are competent in their field.
\end{abstract}

Key words: E-work, e-recruitmen, SDLC.

\section{Introduction}

The process of applying for a job is the first step for a person to get a job that matches the criteria. from the past to the current technological era, the implementation process to continue to grow. At first one should come to the company to look for job vacancies and then apply for jobs based on vacancies available in the company. There are also companies that publish job vacancy information in places posted in the Manuscript place. The next thing is the prospective worker will make a cover letter to the company concerned. After the company receives a letter of introduction from the prospective worker, the human resources will select the worker who meets the criteria, the potential and the quality. However, an accurate information process about someone who is difficult to do with human resources should filter only from the perfect style of cover letter until the end of the interview.

Now there is an e-recruitment system like LinkedIn, Reed, and Indeed for workers looking for work. On this site, workers should write the email address, name, gender, education and salary desired. In accordance with the data entered, the system will provide relevant company links with available job vacancies. So, this system will be used to send emails to prospective workers that may be accessible on system [1].

However this system is ineffective because the prospective worker simply enrolls on the web e-recruitment and awaits notification of the company that is opening a job. Then the prospective worker opens the company's own link and submits himself to the company. because e-recruitment sites only provide such services.

In contrast the prospective workers and e-recruitment system, recruiters (companies) also have bigger 
problems. In the recruitment process, recruiters (companies) want to get the best candidate with the best quality background in a short time. But recruiters have problems in the process of receiving new job candidates. To open new vacancies, companies need to spend energy, time and cost are not small. Recruiters must pay psychologists, test fees, medical examination fees, interviews, and so on. Certainly, will spend considerable time and cost.

Yujin Lee, et al. (2017), Recruitment sites such as LinkedIn, Reed, and Memang have a large list of professional resumes from jobseekers and job postings posted by recruiters. In this case, it is a very time-consuming task for job seekers to find job vacancies suited to their careers and the conditions they desire. Therefore, an active study on job recommendation (JR) has been conducted recently. In this paper, they attribute the most important of the previously neglected. To enter properties into JR, they first used two data modeling methods for adjacent couples and all those working with one [1].

Haddadi Lynda, et al. (2017), presents a new e-recruitment system based on MOOC as the main recruitment. This system is used to assist recruiters in the process both from the recruitment process, by providing access to a large profile database with multiple criteria to get the best. This system has two objectives: first, recruiters help find the best, can integrate their organization and, both to attract a large number of young people and job seekers MOOC platform seen by recruiters through this system [2].

Tomy, Septian Purnomo (2013), Recruitment is important for organization because it has function of collecting human resources toward the organization, the technology development has grown up and it forces Company to apply what is called as e-recruitment which is internet-based recruitment. There are some differences in this system compared to traditional recruitment system. However, the difference is not problem because company gain many advantages from the online system, which are cost efficiency, easy-to-use by candidate, easy-to-use by organization, increasing speed of recruitment process and the success of finding potential employees. Despite of the imperfect theory about the ideal implemention that company can implement the system successfully, some big companies like MICROSOFT, ORACLE and BANK OF IRELAND e-recruitment system [3]

Dr. R. Ramaabaanu, et al. (2014), according with paper. E-recruitment have an importance and problem. The following are the importance of E-recruitment such as Reduced time-to-hire, Reduced cost-of-hire, Wider reach for employers, Wider reach for candidates, State-of-the-art filtration tools, Branding opportunity for employers, Sophisticated management tools, Allows, for confidentiality and Allows for proactivity. E-recruitmen also have a problem such as difficult for a company recruiter to determine whether or not an applicant is the right fit for a job without meeting him/her face-to-face. A candidate can have all the right credentials on paper but still may not have the right character for the company. The most effective way to determine if an applicant is suitable for a particular job and right fit for the company is to meet with him/her face-to-face in an interview and the other problem was Aforementioned on the recruiting side, outdated job postings is the second biggest drawbacks of online recruitment that job applicants detest. Many applicants claim they have applied for what appeared to be a current job posting, only to find out weeks later that the position had been filled a month ago. How devastating this is for individuals who are hoping to land an interview with a prospective employer. Had the aspirant known the position was filled; he/she would have never applied for it. This is simply a total waste of the applicant's time [4].

The e-recruitment system only accommodates prospective employee data with educational background, work field and salary desired. Then from the data, the system will find the company in accordance with data that has been filled by prospective workers. Then send the company link to the prospective worker who then prospective workers will repeat mandasangkan on e-recruitment system provided by the company. The company will select candidate workers. The purpose of this paper is, the authors want to build a system 
to accommodate both, namely prospective workers and companies. All the selection will be done by this e-requruitment system, the company only requests and determines the requirements needed to become a worker in the company then the system will find the appropriate candidate workers and send the candidate's data to the company. So, the company finds the candidate workers who fit the criteria required by the company quickly and effectively. Only provides such services.

\section{Theoretical Basis}

Currently, to find the ideal profile, and besides the classic methods of the recruitment (Advertisements in newspapers, job fairs, hiring events...), large and small ompanies, are heading towards the online recruitment "E-recruitment ». The latter can be broadly defined as the use of new information and communication technologies (particularly Internet) in the management of the recruitment process. Many companies recruit via the web, which is considered as a real source of recruitment. To do, companies add a "career" section to their websites, or disseminate their job offers on websites dedicated to employment and recruitment. These latter play intermediaries' role between the job seekers who can file their CVs, and companies, which can also file their offers to attract new candidates.

E-Recruitment is a method of recruiting new prospective workers to the company by passing all the stages that have been given by the company and using modern electronic communication media such as internet, so that recruitment can be implemented effectively and efficiently to get the workforce according to the need company [5].

In a similar way, recommender systems in the automatic recruitment tasks, allow to HR agents to advertise a job offer in the relevant job board, which may attract the best candidates in a small temporal period. Actually, there are several thousands of dedicated job boards for job offers broadcasting, eg: Monster indeed, iquesta, jobsite, parisjob. Some of them are paying with a subscription. Consequently, searching and identifying the best job board for a new job offer can be considered as a challenging and hard task [6].

\section{Methodology}

Research methodology is a process or scientific way to get data to be used for research purposes. The methodology is also a theoretical analysis of a method or method.

This research uses R \& D (Research \& Development) method and design method of e-recruitment application using SWDLC (Software Development Life Cycle) with Waterfall approach. The Waterfall approach is the basis of process activities consisting of specifications, development, validation, evolution and all represented in separate process stages ie requirements specification, software design, implementation, testing, and so on. The research took the form of case study and research using Research and Development method. Needs in system design using linear sequential model with Waterfall approach. Data collection techniques use interviews, observation and study of all employee acceptance documents so far. Respondents in this study include existing employees and prospective new employees with accidental sampling technique [7].

As for some this research will go through several stages. The stages in this research can be modeled on the diagram of systems development life cycle (SDLC) shown in Fig. 1.

1) System of Planning (Planning)

Planning system is done to form a strategic work structure and the importance of E-Work information system that will be built for users of the system in job search. The planning of this system is done to take into account the resources required in making the system, including hardware, software and human devices as system users.

2) System of Analysis (Analysis) 
System analysis is done by means of process of assessment, identification and evaluation of component and mutual relationship related to system development, problem definition, objectives, needs, priorities and system constraints, advantages and estimation for solutions that can be used to solve existing problems. While the resulting report provides a foundation for establishing a system project team and initiating a phase of system analysis.

3) System of Design (Design)

The design process will translate the requirement into a predictable software design before program code is generated. This process focuses on: data structure, software architecture, interface representation, and procedural (algorithm) details. This document will be used to perform system-making activities.

4) Program Code (Coding)

Coding is a translation design in a language that can be recognized by a computer. At this stage the system design is implemented into the program code. Programming begins by creating programs with PHP programming languages and MySQL databases.

5) Test of System (Testing)

After the coding is complete it will be tested against the program that has been made. The purpose of program testing is to find errors on the system and then fix it. How to test the program is done by using the program as a whole to know the database connection and the smooth processing of data.

6) Maintenace of system (Maintenance)

The finished software is tested, then it will be implemented into the system owned by the system user, once everything goes according to plan, then the next system maintenance is done. This is necessary because the system is designed to require changes due to errors or developments in the field of information technology.

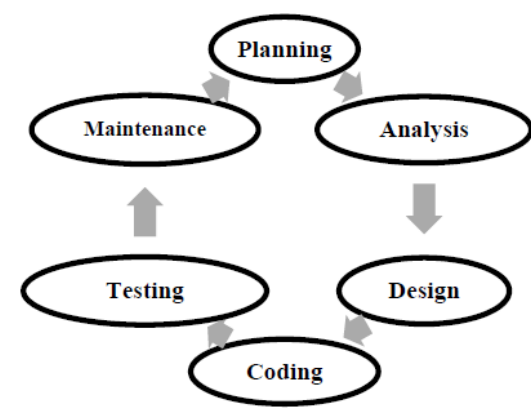

Fig. 1. Diagram of SDLC research methodology.

\subsection{Flow Analysis}

In the current e-recruitment systems such as LinkedIn, Reed, and Indeed and so on, this system provides and accommodates all prospective workers into the system which will then be assisted to search for jobs. In the initial registration, this system will ask the user (prospective workers) input email address, name, majoring education, work field and salary range in want. After the data is completed by all users, then the user data will be entered into the system database. So, if there are companies that want to look for potential workers by requesting certain criteria, the system will select all users whose data has been stored in the system. Users who qualify for the company, will receive the job notification to their email. The system will send the link company and users can directly register themselves on the company's website.

So, from that point, this paper is designed to create heading posts for users (prospective workers) and companies to be on the same system. So, help users in finding work and help companies in finding workers who are competent in their field. 


\section{Analysis and System Design}

\subsection{Analysis System}

In the existing e-recruitment systems such as LinkedIn, Reed, and Indeed, the system provides services to overshadow job seekers so that they will get notified via e-mail companies that are opening vacancies. In the Fig. 2 below will explain the process flow of the existing e-recruitment system.

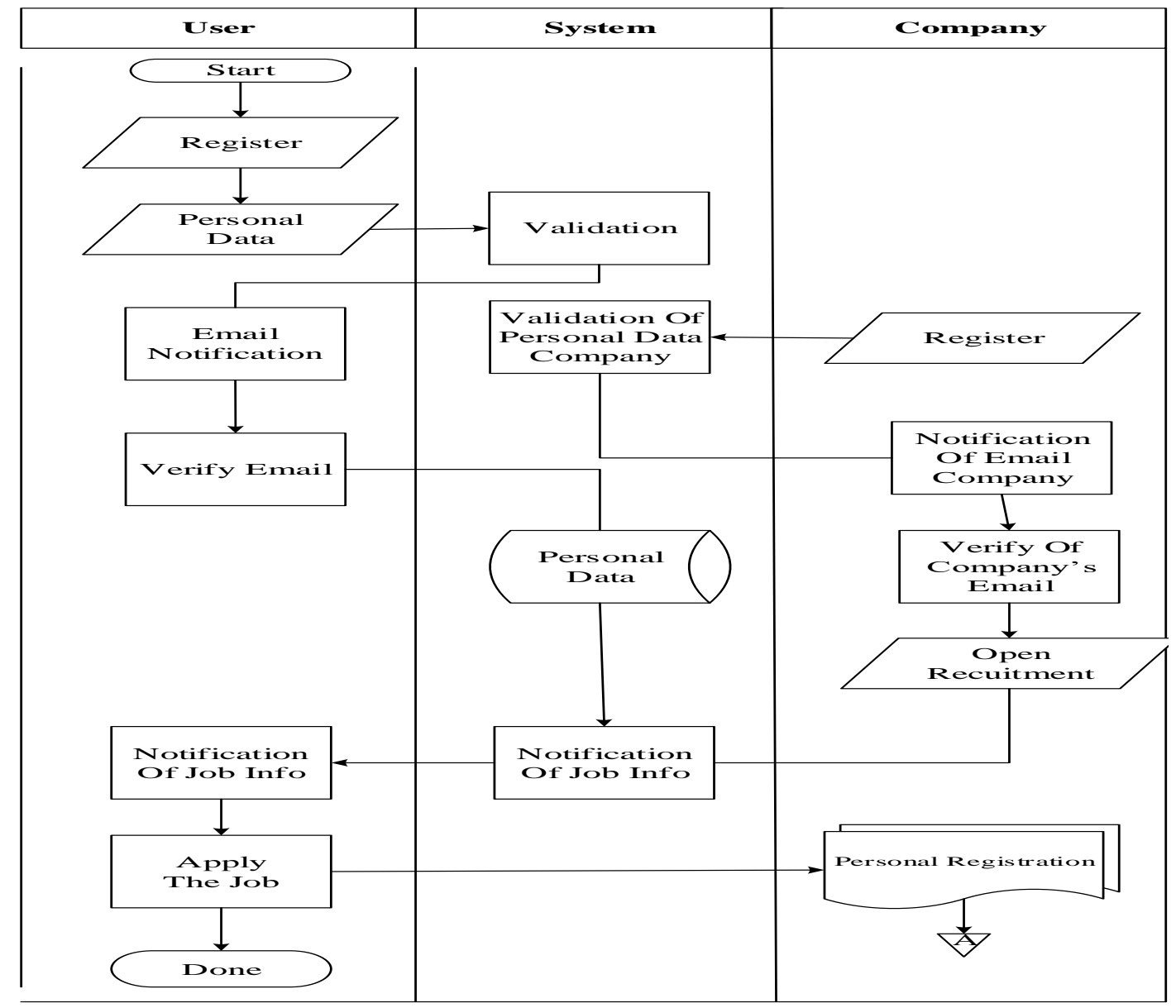

Fig. 2. Flow of document e-recruitment system.

In Fig. 2, shows a flow of document of the current e-recruitment system. Can be seen in the existing system, prospective workers will register themselves on the system, then the system will verify email from prospective workers who will then use the system to provide notification of companies who are opening vacancies. Each prospective worker will get a job posting notification email on their inbox. If they are interested, they will open a link / company website that is opening vacancies and then register themselves on the company. System activity will stop after the system provides job posting notice on the participant's email.

\subsection{Implementation of System}

From this research will produce a new E-recruitmen system(E-work), with the aim of facilitating the job seekers in finding a job. In this study the authors describe the proposed system using Use Case Diagram. Use Case Diagram is a diagram that presents the interaction between Use Case and Actor. Use Case is used to facilitate in analyzing scenarios that we will use in subsequent phases by assessing the scenario. The following is the Use Case Diagram new E-recruitmen system (E-work) shown in Figure 3. 


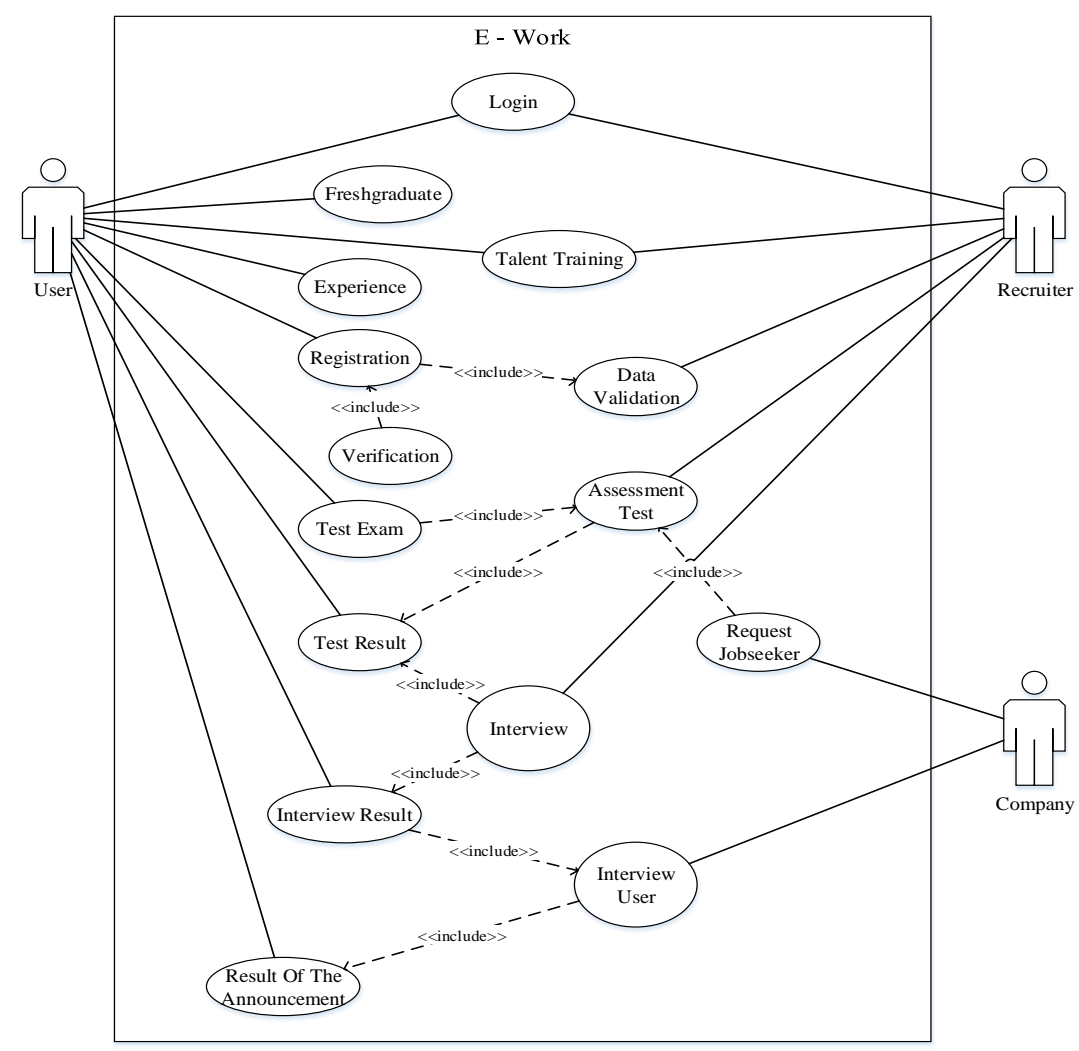

Fig. 3. Use case diagram of new e-recruitment system.

Users and admins will log into the e-work system. Users will do the data self regitrasi, admin will validate the data then the system will send verification of truth data to user so user can continue at next stage. Users will upload important data such as diplomas, certificates and fortopolio from the user. The system will differentiate the working status class from the user. Differentiated job status is fresh graduate and experienced. The system will automatically group these users.

The advantages of this system from the usual recruitment system in use, this system is a complex system for job seekers. In the old system, the job seekers only register on the system then the system will provide a notification to email users, companies that are opening vacancies. The system only provides website links and then the users themselves who register themselves on the company.

In this new system, many new features are on offer so it will be helpful for companies looking for workers and workers looking for work. This system provides the feature "Training of talents". The usefulness of this feature is as a matriculation of job seekers in order to gain competent and competent competence with their field of knowledge. This system works with reliable and trusted training agencies. The system works with one of the best psychologists and trusted national institutions. So companies need not hesitate to exam conducted by this system.

This system provides the exam features and the test results will be rated by someone who is competent in their field. The test results of the participants will be stored by the system which will then be forwarded to the company looking for workers with certain conditions. Because the system offered here is a system by request. Companies are free to determine the terms and processes desired. And the system will prepare workers according to the criteria companies want. Selection process in the desired also may be requested by the company.

\section{Conclusion}

From the results and research can be summed up some things as follows: 
1) Job-seekers and companies have shelter in the same system.

2) The system will perform work tests for prospective workers, accumulate the wealth and experience of prospective workers.

3) Searchers facilitated in the registration because the data already stored in the database can be used to apply in some companies.

4) The system facilitates the company to find qualified and qualified workers with the company's request.

5) The company does not need to take a long time to find a suitable job candidate.

6) Prospective workers who are given to the company can be guaranteed his expertise because the e-recruitment system has tested the prospective workers before.

7) Saves the cost of hiring new prospective workers.

\section{Suggestion}

From the results and research there are several suggestions that can be given below:

1) The development of e-recruitment application needs to be adjusted to the needs and development of the company's business. Employee recruitment conducted online must pay attention to the security of corporate data and data of each member.

2) Lack of application of database security pattern in e-recruitment application will result in inaccurate data member even can cause data loss. Therefore, need to develop some security pattern especially on registration form member and member login.

\section{References}

[1] Lee, Y. J., et al. (2017). Exploting job transition patterns for efective job recommendation. IEEE International Conference On Systems, Man, And Cybernetics (SMC). Banff Center, Banff, Canada,

[2] Haddadi, L., et al. (2017). E-recuitment support system based on MOOCS. Proceedings of International Conference on Mathematics and Information Technology.

[3] Tomy, S. P. (2013). Recruitmen online (e-recruitment) sebagai suatu inovasi dalam perekrutan perusahaan. Jurnal JIBEKA, 7(3).

[4] Ramaabaanu, R., et al. (2014). Importance and problem of e-recruitmen. International Journal of Research (IJR), 1(9).

[5] Muhamad, I., et al. (2014). Rancangan aplikasi e-recrutment pada PT. kalila Indonesia. Seminar Nasional Teknologi Informasi Dan Komunikasi 2014.

[6] Sidahmed, B., et al. (2017). Predicting the users clickstreams using time series representation symbolic sequences, and deep learning: Application on job offers recommendation tasks. Proceedings of IEEE International Conference on Information Reuse And Integration.

[7] Gat, S. K. (2014). Pengembangan aplikasi e-recruitment dalam perekrutan karyawan. Eksplora Informatika, 3(2).

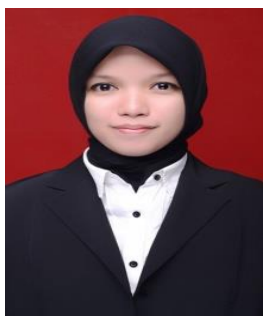

Fanny Ramadhani was born 25 years ago. She holds a bachelor degree from the Department of Computer Science, University of Sumatra Utara in 2016. Since 2014, She became a teacher at one of the vocational schools in the field. She teaches about the network and servers in the school. During school, he has the responsibility to get students to successfully create all the servers and administrate the servers on the network. Currently she is completing his studies to obtain a master's degree at the University of Sumatra Utara. 
Prof. Dr. Muhammad Zarlis, M.Sc is one of the professors at the University of North Sumatra. He is also the head of majors in Informatics Engineering in University Of Sumatera Utara. He earned his bachelor's degree in Physics in 1984 at the University Of Sumatera Utara. He also earned his master's degree in computer science at University Of Sumatera Utara in 1990. And in 2002 he earned a doctorate in Computer Science at Universiti Sains Malaysia. As Member of Development of Communication and Information Technology, Indonesian Professor Association, 2013-2017 period, Prof. Zarlis, who always appeared as a young man, has experience on how to negotiate with the management of a banking institution to create a more humanist system, which is a very valuable lesson for policy makers. 